\title{
Structured Health Literacy Intervention for Mothers Regarding Stem Cells Therapy
}

\author{
Ohoud Youssef El-Sheikh ${ }^{1}$ Rasha A. Mohamed ${ }^{2} \quad$ Mohamed Zoromba $^{3} \quad$ Ahmed Noaman $^{4}$ \\ 1.Lecturer of Pediatric Nursing, Faculty of Nursing, Mansoura University, Egypt \\ 2 .Lecturer of Community Health Nursing, Faculty of Nursing, Mansoura University, Egypt \\ 3. Lecturer of Psychiatric Nursing and Mental Health, Faculty of Nursing, Mansoura University, Egypt \\ 4.Lecturer of Pediatrics, Faculty of Medicine, Mansoura University, Egypt
}

\begin{abstract}
Background: Stem cells have tremendous promise uses for the future to treat a variety of diseases, injuries, and other health-related conditions. Their potential is evident to promote the repair response of diseased, dysfunctional or injured tissue. Aim: This study aimed to assess the effectiveness of applying a structured health literacy intervention regarding stem cells therapy (SCT) on the mothers' level of knowledge and attitude. Methodology: A quasi-experimental one-group pre-post test design was utilized. The study involved 302 mothers recruited from the pediatric outpatient clinics of Mansoura University Children Hospital (MUCH), Egypt. Data were collected using two structured interview sheets (knowledge and attitude). Results: There were highly statistically significant differences in mothers' knowledge and attitude one-month post-application of the structured health literacy intervention regarding stem cells therapy compared to pre-application $(P=<0.001)$. Conclusion: Application of a structured health literacy intervention showed a significant improvement in mothers' level of knowledge and attitude regarding stem cells therapy.
\end{abstract}

Keywords: Attitude, Health Literacy, Knowledge, Stem Cells Therapy.

DOI: $10.7176 / \mathrm{JHMN} / 61-06$

Publication date: April $30^{\text {th }} 2019$

\section{Introduction}

The utilization of stem cells as a therapeutic option for currently disabling diseases holds fascinating potentials (Bae, 2013). Stem cells are repaired units of the body that serve a central function in the maintenance and regeneration of organs and tissues throughout an organism's lifetime. Their chief function is to replenish dying cells and regenerate damaged tissues (Slack, 2018). Perhaps more than any other industry, stem cell therapies are poised to make a significant impact all over the world on public health, and many individuals living today may experience stem cell-related therapies. Stem cell therapy is currently being applied to over 50 diseases including heart, lung, neurodegenerative, and eye diseases, cancer, and HIV (DeWindt, et al., 2014).

Multiple sources of stem cells from the human body were accessed as in the remaining blood within the umbilical cord and the placenta which is known as umbilical cord blood stem cell. The stem cells from the umbilical cord can be kept in the private banks until the need of the child or his family within a determined cost. Also, there are public banks similar to blood banks to preserve umbilical cord blood stem cells' (Pandey et al., (2016). The amniotic fluid may be kept for use in the future to treat other conditions either during gestation or after birth. It is broadly recognized as a potentially life-saving source of powerful stem cells for many current and emerging treatments of babies and their siblings (Patyal et al., 2018).

In Egypt and the Middle East, the Cell Safe Bank is the first stem cell bank, obtained its license from the Ministry of Health in 2009. It was accredited internationally by the American Association of Blood Banks (AABB). Currently, there are 720 stem cell banks worldwide, only 76 of them were accredited by AABB, proudly Cell Safe Bank is one of these (https://www.cellsafebank.com/). In 2011, the Egyptian Ministry of Health forms the national committee of stem cells, with a membership group of professors in different disciplines, tasked with constructing regulations for stem cells research and therapy and a national stem cell bank. Also, initiated a new stem cell research center at Sheikh Zayed Hospital in 2012, and Zewail City of Science and Technology opened a center for stem cell research and regenerative medicine in 2013 (Matsumoto et al., 2015).

Health literacy is a significant determinant of health and become an important public health concern that receiving growing interest in recent years because of its cardinal role in health education and promotion as well as it involves cultural influences on both the professional and the public (Kickbusch, et al., 2017). It is considered a measure to assess the public awareness towards any health problem that contains three elements to assess: basic knowledge and beliefs, knowledge and attitudes toward health-related behaviors and lifestyles, and basic skills (Shen et al., 2015).

From the public health perspectives, health literacy is a extensive concept that encompasses an individual's understanding of and ability to use health information and ability to navigate a complex health care system (Sørensen et al., 2013). Many factors of the public health system affect how people understand and use health information, such as the following: communication skills of public health professionals, level of difficulty and 
novelty of the health information, cultural and linguistic suitability of health information, services, and public health infrastructure that facilitates and supports healthy behaviors (Jackie Foster, et al., 2016).

Health literacy refers not only to the skills and abilities of patients but also of those providing health education and care, including nurses (Kickbusch, et at., 2017). Health care providers particularly nurses who are the trusted source of information for most patients should be able to provide health education services to patients on the new concept of stem cells use, benefits and its practice implications (Tork et al., 2017).

Knowledge and attitude about stem cell and cord blood banking is insufficient among mothers. In addition, in developing countries little is known regarding the effectiveness of community education to increase the number of stem cell donors (Pandey et al., 2016). Furthermore, nurses who grant quality care and act as a tutor and counselor have a crucial role to provide health literacy intervention to mothers about the significance of stem cells therapy. Harris et al., (2015) reported that when the parents' had enough health information related to a defined health problem they had the ability to make decisions concerning health care, disease prevention, and health promotion.

\section{The significance of the study}

Health literacy is an essential component of health-related quality, health behaviors and communications, and access to health care. The experimental studies have specified significant associations between the unsatisfactory level of health literacy and poor health outcomes. In the $21^{\text {st }}$ century, many diseases had propagation, especially among children, such as oncology, orthopedics, type 1 diabetes mellitus, cardiac valvular diseases, and others (Peberdy et al., 2018). There was a revolution in developing therapies by stem cells at the last 20 years. This revolution explains the capabilities of stem cells in treating many of diseases that cannot be treated before. The stem cells therapy is considered a hopeful way for mothers who miss the hope in treating their children suffering from chronic diseases. The promises of treatment for human ailments by stem cells have been much touted but many obstacles must be overcome. One of these obstacles is the lack of awareness of mothers and confused attitudes toward the innovation of stem cells therapy. These obstacles inspire the researchers to apply this study for improving mothers' level of knowledge and attitude regarding stem cells therapy, as their support is crucial to the success of cord blood transplant programs.

\section{Subjects and methods}

\section{Aim of the study}

This study aimed to assess the effectiveness of applying a structured health literacy intervention regarding stem cells therapy on the mothers' level of knowledge and attitude. This aim can be achieved through:

1. Determine the mothers' level of knowledge regarding stem cells therapy.

2. Identify the mothers' attitude towards stem cells therapy.

3. Apply the structured health literacy intervention regarding stem cells therapy on the selected mothers.

4. Evaluate the effectiveness of health literacy intervention regarding stem cells therapy on the mothers' level of knowledge and attitude.

\section{Research hypothesis}

Application of the structured health literacy intervention will improve the mothers' level of knowledge and attitude regarding stem cells therapy.

\section{Study design \& Setting}

A quasi-experimental one-group pre-post test design was utilized to fulfill the aim of this study. The current study was conducted at the pediatric outpatient clinics of Mansoura University Children's Hospital (MUCH), Egypt. The total number of these clinics are (12 clinics) including various specialties of pediatrics care; general surgery, endocrine, urology, malnutrition, infectious diseases, blood diseases, genetics, digestive diseases, cardiac, allergy, neurosurgery, and cardio surgery clinic.

\section{Sampling}

A convenient sample of 302 mothers attended the pediatric outpatient clinics of Mansoura University Children Hospital (MUCH) and accepted to participate in the study was selected. The mothers were eligible for the study if she had a child suffering from chronic diseases as (type 1 diabetes mellitus, blood disorders, myocardium diseases, gastrointestinal disorders, neurological diseases, and cancer). There were no limits in regards to parity, occupation, or level of education.

\section{Tools of data collection}

The researchers in a simple Arabic language designed two structured interview sheets after reviewing the relevant literature (Saran et al., 2015 and Raju, 2018). The tools were utilized through face-to-face interview pre and post- 
application of the structured health literacy intervention.

Tool (I): Part (a): Socio-demographic questionnaire to gather information related to mothers' age, marital status, and educational level.

Tool (I): Part (b): Mothers' knowledge structured interview sheet to determine the mothers' level of knowledge regarding stem cells therapy. It was classified into five main categories; these categories were composed of (30) multiple choice questions covering information related to; concepts, types, sources, uses and applications of SCT in treating medical diseases, storage and donation of stem cells. The scoring system for the knowledge tool was determined; the correct answer marked (1) and an incorrect answer marked (zero). The total scores ranged from (0-30 marks) as the following; understanding the concepts of stem cells therapy (7 marks), types of stem cells ( 3 marks), sources of stem cells ( 3 marks), uses and applications of SCT in treating medical diseases ( 8 marks), and storage and donation of stem cells and cord blood ( 9 marks). The mothers were considered that they have had a good level of knowledge if the percent score was more than $65 \%$ of the total score $(19.5$ marks); the fair level was between $50 \%$ to $65 \%$ (15- 19.5 marks) and poor level of knowledge when the score was less than $50 \%$ ( 0 - less than 15 marks).

Tool (II): Mothers' attitude structured interview sheet to determine the mothers' attitude regarding stem cells therapy. It was consisted of ten statements. Three-point Likert scales with three continuums "agree, uncertain, disagree" ( 2,1 and zero respectively) was used. If the statement was negative, the scoring system was reversed in SPSS as 2 marks were given to disagree, 1 mark was given to uncertain, and zero was given to agree. The total scores of the attitude ranged from ( $0-20$ marks) as the following; safety uses and applications of stem cells (included 6 items $=12$ marks), and future storage and donation of stem cells and cord blood (included 4 items $=8$ marks). The mothers were considered that they have had a positive attitude if the percent score was $60 \%$ of the total score and more and negative attitude if the percent score was less than 60\% (Hans and Kaur, 2016).

\section{Validity and reliability}

Face and content validity of the tools for clarity, comprehensiveness, appropriateness, and relevance by a board of seven experts in nursing education were done. The board ascertained the face and content validity of the tools. Examination of content validity index (CVI) showed that CVI $=86 \%$. Reliability was assessed through Cronbach's Alpha reliability test $\alpha=89 \%$ which revealed that each of the two tools were consisted of relatively homogenous items as indicated by the moderate to high reliability of each tool.

\section{Health literacy intervention regarding stem cells therapy}

Before conducting the study, official permission from the faculty of nursing was produced to the appropriate authorities in the chosen setting. Permission to conduct the study at the selected setting was obtained after clarifying the aim of the study in addition to gaining their cooperation and support during data collection. A review of local and international literature was completed on various aspects of stem cells therapy utilizing scientific published articles, web search, and textbooks.

The preliminary data concerning the mothers' knowledge and attitude regarding stem cells therapy was gathered. The first and second researchers obtained verbal consent from each mother after the aim of the study was clarified. The mothers were informed that their participation in the study was voluntarily and they had the right to withdraw from the study at any time without giving a reason. Confidentiality of information was also ensured.

The structured health literacy intervention of the study was designed by the first and second researchers based on the obtained preliminary data and according to health literacy principles. The contents of health literacy intervention included (concepts, types, sources, uses and applications of SCT in treating medical diseases, storage and donation of stem cells). It was reviewed by experts in the nursing and medical field. (Kickbusch et al., 2017)

The intervention sessions about stem cells therapy using brochures were presented to the mothers in simple Arabic language at the health education room of the selected hospital. Two sessions were given to every group of mothers (5-7 mothers). Every session consumed 40 minutes to be finished. The evaluation was applied by comparing mothers' knowledge and attitude related to stem cells therapy using the same interview sheets pre and one-month post-application of the health literacy intervention sessions by the third and fourth researcher.

\section{Ethical considerations}

Ethical approval was obtained from the Ethical Research Committee at the Faculty of Nursing, Mansoura University to carry out the study. Verbal consent was taken from the mothers after clarifying the aim and process of the study. Confidentiality was ensured throughout the study process. The mothers were confirmed that all data were used only for research purpose. Finally, the mothers were informed that refusing the participation or even withdrawal at any time from the study were their rights. 


\section{Data collection}

For data collection, the mothers were face-to-face interviewed by using structured interview sheets that administered before starting each session through two stages pre and post-application of health literacy intervention. Each interview sheet took a period ranged from 15-20 minutes. About 5-7 sheets were fulfiled/day (3 days/week). The total time spent on data collection was six months starting from February to the end of July 2018

\section{Pilot study}

A pilot study was carried out on 30 mothers (10\% of the study sample) excluded from the total sample who attended to the outpatients clinics of Mansoura University Children Hospital. It was done to notice any ambiguity in the tools, to ensure transparency of the items, as well as, to find out the time devoted to data collection. Needed modifications were carried out based on the results of the pilot study to develop the final form of the tools.

\section{Data analysis}

Data were analyzed with Statistical Product and Service Solution (SPSS version 24 Inc., Chicago, IL, USA). The normality of data was firstly tested with a one-sample Kolmogorov-Smirnov test. Qualitative data were described using numbers and percentages. Continuous variables were presented as mean \pm SD (standard deviation) for parametric data. T-test was used for comparison between 2 paired within one group. ANOVA test was used for comparison between and within groups. Pearson correlation coefficients were used to estimate the correlation between the study variable to clarify positive or negative correlation. For all above-mentioned statistical tests done, the threshold of significance was fixed at $5 \%$ level ( $P$-value). The results were considered significant when the probability of error is less than $5 \%$, non-significant when the probability of error is more than $5 \%$, and highly significant when the probability of error is less than $0.1 \%$. The smaller the $p$-value obtained, the more significant are the results.

\section{Results}

Table (1); Frequency distribution of socio-demographic characteristics for the studied mothers

\begin{tabular}{|c|c|c|}
\hline Socio-demographic characteristics & $\mathrm{N}=\mathbf{3 0 2}$ & $\%$ \\
\hline \multicolumn{3}{|l|}{ Age/years } \\
\hline $21:<40$ ys & 267 & 88.4 \\
\hline $40:<55$ ys & 35 & 11.6 \\
\hline \pm S.D & \multicolumn{2}{|c|}{$32.83+7.5$} \\
\hline \multicolumn{3}{|l|}{ Educational level } \\
\hline Did not read or write & 37 & 12.3 \\
\hline Read and write & 45 & 14.9 \\
\hline Intermediate education & 99 & 32.8 \\
\hline Higher education & 121 & 40.0 \\
\hline \multicolumn{3}{|l|}{ Occupation } \\
\hline Working & 157 & 52 \\
\hline Housewife & 145 & 48 \\
\hline \multicolumn{3}{|l|}{ Marital } \\
\hline Married & 250 & 82.8 \\
\hline Divorced & 24 & 7.9 \\
\hline Widow & 28 & 9.3 \\
\hline \multicolumn{3}{|l|}{ Residence } \\
\hline Rural & 160 & 53 \\
\hline Urban & 142 & 47 \\
\hline
\end{tabular}

Table 1 portrayed that the majority of the studied sample (88.4\%) were between 21-40 years of age and $(82.8 \%)$ are married. With respect to their educational level, more than one-third $(40.1 \%)$ of the studied mothers completed their higher education. In addition, $(52 \% \& 53 \%)$ of them are working and living at rural area respectively. 
Table (2); Mean differences of mothers' knowledge scores pre and post-application of the structured health literacy intervention regarding stem cells therapy

\begin{tabular}{|l|c|c|c|c|c|c|}
\hline \multicolumn{1}{|c|}{ Mothers' knowledge items } & \multicolumn{2}{c|}{$\begin{array}{c}\text { Pre- } \\
\text { application }\end{array}$} & \multicolumn{2}{c|}{$\begin{array}{c}\text { Post- } \\
\text { application }\end{array}$} & \multicolumn{2}{c|}{ Test of Sig } \\
\cline { 2 - 6 } & & SD & & SD & t & P \\
\hline Understanding the concepts of stem cells therapy & 1.57 & 0.55 & 5.29 & 0.95 & 10.27 & $0.000^{*}$ \\
\hline Types of stem cells & 1.39 & 0.43 & 2.28 & 0.82 & 10.38 & $0.000^{*}$ \\
\hline Sources of stem cells & 1.1 & 0.34 & 2.14 & 0.66 & 12.55 & $0.000^{*}$ \\
\hline $\begin{array}{l}\text { Uses and applications of SCT in treating medical } \\
\text { diseases }\end{array}$ & 1.61 & 0.53 & 6.01 & 0.87 & 12.83 & $0.000^{*}$ \\
\hline Storage and donation of stem cells and cord blood & 3.58 & 0.64 & 6.37 & 1.14 & 12.49 & $0.000^{*}$ \\
\hline The total mean score of knowledge (30 marks) & 9.25 & 2.49 & 22.1 & 4.44 & 13.15 & $0.000^{*}$ \\
\hline
\end{tabular}

It was clear from table 2 that there were statistically significant differences in the studied mothers' knowledge about stem cells therapy in area related to concepts, types, sources, uses and applications of SCT in treating medical diseases, storage and donation of stem cells and cord blood post-application of the structured health literacy intervention compared to pre-application as reflected in the mothers' total mean scores of knowledge $(\mathrm{t}=13.15 \mathrm{P}=$ $0.000)$.

Figure 1; Distribution of the studied mothers' knowledge level pre and post-application of the health literacy intervention regarding stem cells therapy

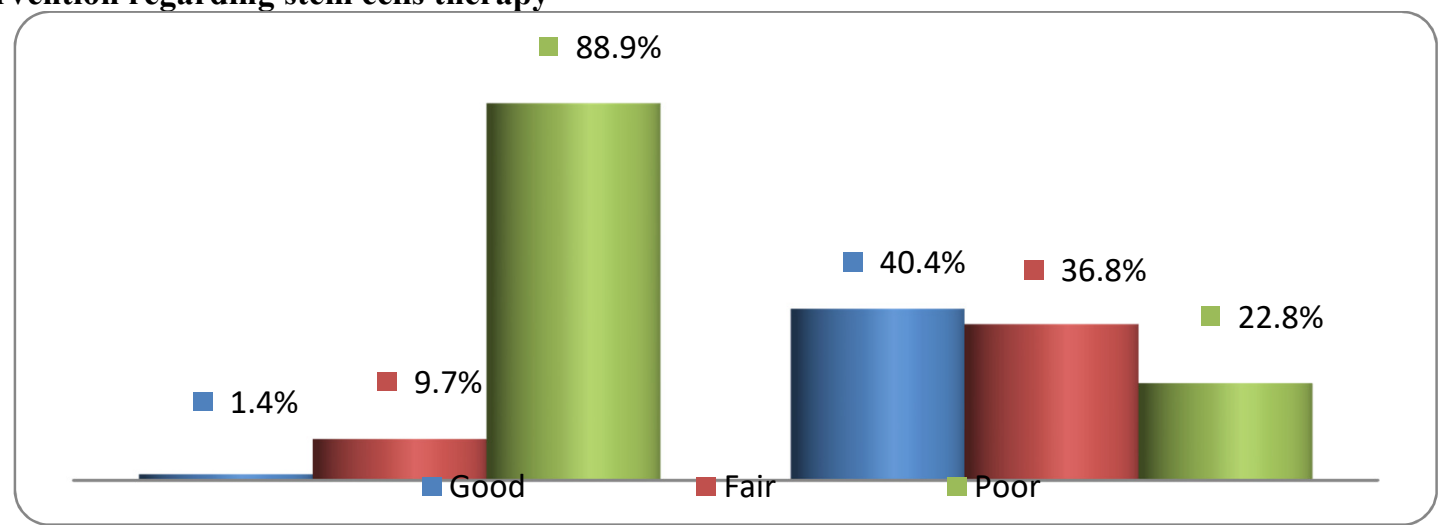

Good $=$ more than $65 \%$ of total scores. Fair $=50 \%$ to $65 \%$ of total sores. Poor $=$ less than $50 \%$ of total scores

Pre-application of the structured health literacy intervention revealed that $(88.9 \%)$ of the mothers showed poor score level of knowledge compared to $(1.4 \%)$ who showed a good score. However, post- application of intervention (36.8\% and 40.4\%) of them showed fair and good score level of knowledge respectively as presented in Figure (1).

Table (3); Mean differences of the studied mothers' attitude scores pre and post-application of the health literacy intervention regarding stem cells therapy

\begin{tabular}{|c|c|c|c|c|c|c|}
\hline \multirow[t]{2}{*}{ Mothers' Attitudes } & \multicolumn{2}{|c|}{ Pre-test } & \multicolumn{2}{|c|}{ Post-test } & \multicolumn{2}{|c|}{ Test of Sig } \\
\hline & & SD & & SD & $\mathbf{t}$ & $\boldsymbol{P}$ \\
\hline Safety uses and applications of stem cells (12 marks) & 3.47 & 0.84 & 10.3 & 0.91 & 10.860 & $0.000 *$ \\
\hline Future storage and donation of stem cells & 1.54 & 0.23 & 4.75 & 0.79 & 1.342 & $0.018^{*}$ \\
\hline Total mean attitude score ( 20 marks) & 5.01 & 1.07 & 15.1 & 1.7 & 5.819 & $0.000 *$ \\
\hline
\end{tabular}

t: paired sample t-test $\boldsymbol{P}$ : Significance $*$ Significant $(\mathrm{p} \leq 0.05)$

Table (3) shows that there were statistically significant differences in the studied mothers' total attitude score regarding stem cells therapy related to safety uses, applications of stem cells, the future storage and donation of stem cells and cord blood post-application of the structured health literacy intervention with a mean of $15.08 \pm 2.17$ compared with pre-application with a mean of 5.01 $\pm 2.87(\mathrm{t}=5.819, \mathrm{P}=0.000)$. 
Figure 2; Distribution of the studied mothers' attitude pre and post-application of the health literacy intervention regarding stem cells therapy

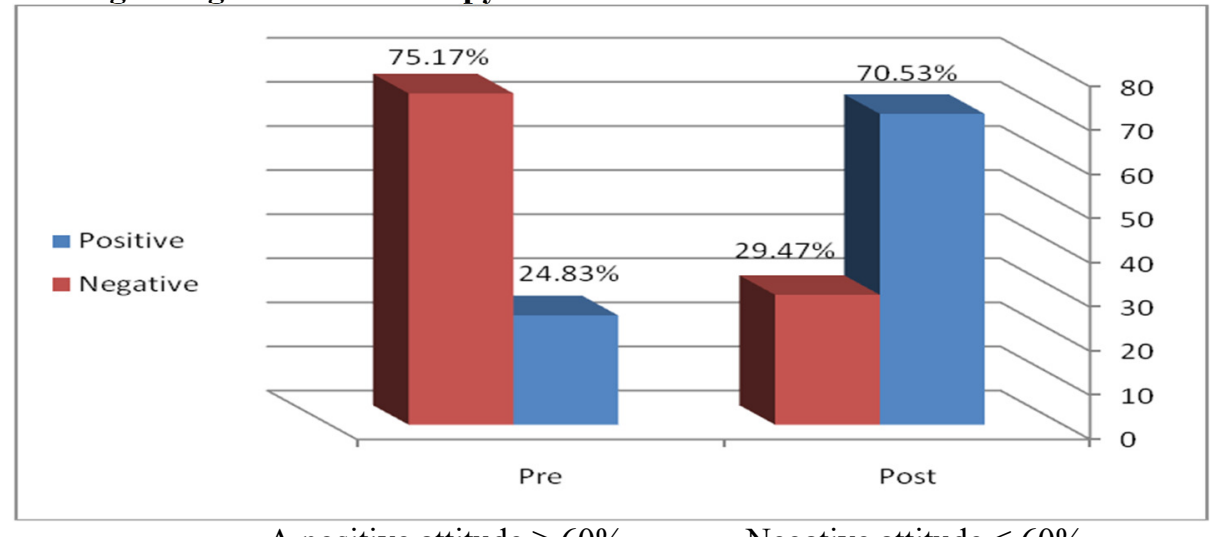

A positive attitude $\geq 60 \%$

Negative attitude $\leq 60 \%$

Figure (2) presents distribution of the studied mothers' attitude toward stem cells therapy pre and postapplication. It was observed that $(24.83 \%)$ of the studied mothers had a positive attitude toward stem cells therapy pre-application of health literacy intervention compared to $(70.53 \%)$ post-application.

Table (4); Correlation between mothers' knowledge and attitude post-application of the health literacy intervention regarding stem cells therapy

\begin{tabular}{|c|c|c|}
\hline \multicolumn{1}{|c|}{ Items } & $\mathbf{r}$ & $\boldsymbol{P}$ \\
\hline Knowledge and attitude & .681 & $0.000^{*}$ \\
\hline
\end{tabular}

r: for Pearson correlation $P$-value significant if $\leq 0.05$ If $\mathrm{r} \leq 0.5=$ weak correlation If $\mathrm{r}>0.5=$ strong correlation

Table (4) shows a significant, positive correlation between the total score of knowledge and total score of attitude post-application of the health literacy intervention regarding stem cells therapy $(\mathrm{r}=.681 P=0.000)$. This clearly indicates that when the knowledge level was increased, the attitude was changed positively regarding stem cells therapy among the studied mothers.

Table (5); Relation between socio-demographic characteristics of the studied mothers and knowledge and attitude pre and post-application of the structured health literacy intervention.

\begin{tabular}{|c|c|c|c|c|c|c|c|c|}
\hline \multirow{3}{*}{ Items } & \multicolumn{4}{|c|}{ Total knowledge pre-application } & \multicolumn{4}{|c|}{ Total attitude post- application } \\
\hline & \multicolumn{2}{|c|}{ Pre } & \multicolumn{2}{|c|}{ Post } & \multicolumn{2}{|c|}{ Pre } & \multicolumn{2}{|c|}{ Post } \\
\hline & & S.D. & & S.D. & & S.D. & & S.D. \\
\hline \multicolumn{9}{|l|}{ Age/years } \\
\hline $21:<40 y s$ & 8.22 & 1.80 & 20.80 & 4.23 & 5.72 & 0.49 & 15.6 & 2.47 \\
\hline $40:<55$ & 10.28 & 1.34 & 23.43 & 2.65 & 4.21 & 0.39 & 14.7 & 1.76 \\
\hline Test of sig. & \multicolumn{2}{|c|}{$\mathrm{t}=1.016$} & \multicolumn{2}{|c|}{$\mathrm{t}=.806$} & \multicolumn{2}{|c|}{$\mathrm{t}=1.016$} & \multicolumn{2}{|c|}{$t=.199$} \\
\hline $\mathbf{P}$ & \multicolumn{2}{|c|}{0.183} & \multicolumn{2}{|c|}{0.042} & \multicolumn{2}{|c|}{0.183} & \multicolumn{2}{|c|}{0.656} \\
\hline \multicolumn{9}{|l|}{ Educational level } \\
\hline Did not read or write & 8.71 & 1.75 & 21.18 & 3.34 & 4.72 & 1.86 & 15 & 2.63 \\
\hline Read and write & 9.67 & 1.34 & 18.44 & 4.54 & 5.21 & 1.59 & 16.1 & 1.47 \\
\hline Intermediate education & 8.47 & 2.66 & 24.03 & 3.66 & 4.82 & 3.38 & 14 & 1.76 \\
\hline Higher education & 10.14 & 2.04 & 24.38 & 3.22 & 5.36 & 3.68 & 15.1 & 1.68 \\
\hline Test of sig. & \multicolumn{2}{|c|}{$\mathrm{F}=7.852$} & \multicolumn{2}{|c|}{$\mathrm{F}=.641$} & \multicolumn{2}{|c|}{$\mathrm{F}=1.059$} & \multicolumn{2}{|c|}{$\mathrm{F}=.923$} \\
\hline $\mathbf{P}$ & \multicolumn{2}{|c|}{0.098} & \multicolumn{2}{|c|}{0.016} & \multicolumn{2}{|c|}{0.106} & \multicolumn{2}{|c|}{0.043} \\
\hline
\end{tabular}

t: paired sample t-test $\quad \mathbf{F}$ (One way-ANOVA) $\quad \boldsymbol{P}$-value significant if $\leq 0.05$

Table (5) portrays the relationship between socio-demographic characteristics of the studied mothers and knowledge and attitude pre and post-application of the structured health literacy intervention. It was observed that there was a statistically significant difference between total knowledge score and age in post-application of the structured health literacy intervention $(\mathrm{t}=.806, P=0.042)$. In addition, there was a statistically significant difference between total mothers' knowledge score and age in post-application $(\mathrm{t}=.806, P=.042)$. Furthermore, there was a statistically significant difference between total mothers' knowledge score and educational level in pre and post-application $(\mathrm{F}=7.852, P=0.098)$ and $(\mathrm{F}=.641, P=0.016)$ respectively. Moreover, there was a statistically significant difference between total mothers' attitude score and educational level in post-application of the structured health literacy intervention regarding stem cells therapy $(\mathrm{F}=.923, P=0.043)$.

\section{Discussion}

The function of stem cells in repair and regeneration of damaged tissues in different organs like myocardium, lung, 
wound healing, treatment and improving symptoms of neurological diseases and others are developing and have a great beneficial future use. Moreover, the storage preservation of stem cells banking will provide a sort of biological insurance to children and safe their future (Joo and Lee, 2018). According to Venugopal et al., (2016), the benefits of health literacy expansion include a better commitment to treatment, increased connection in selfcare, improved health status, greater effectiveness, and lower costs of the health system.

A study was done by Karagiorgou et al (2014) concluded that women were not sufficiently informed about stem cells therapy and cord blood banking. Furthermore, studies on enhancing mothers' knowledge and attitudes regarding stem cells therapy were very little. From the researchers' point of view this because the therapy of stem cells is a recent discovery and a quite new phenomenon in the field of medical treatment for some diseases, as well as the awareness about SCT among the public, is very little. Furthermore, the mass media did not address this issue adequately. Thus, providing mothers with basic information is very important to improve their knowledge and attitudes positively towards stem cells therapy in the area related to types, uses, indications, banking, and donation of stem cells to future use.

The present study findings have proven the research hypothesis. The current study showed that there was a marked improvement in the mothers' knowledge level and attitude regarding stem cells therapy post-application of the structured health literacy intervention compared to pre-application. This indicates the effectiveness of the structured health literacy intervention that was presented by proper teaching methods with clear and simple language. These results were in accordance with the findings of Edwin Francis et al (2016) who reported that after applying of a structured instructional program, there was a significant difference in knowledge level pre and post-test. In addition, Nisha Philip and Seeta Devi (2017) was in agreement with the current study.

In addition, the results of this present study showed that the total mean scores of mothers' attitude were increased post-application of the structured health literacy intervention compared to pre-application. This finding could be explained by the fact that the health literacy intervention was effective in improving mothers' knowledge and correspondingly their attitude was also improved. These finding goes in line with Poomalar and Jayasree (2016) who studying the awareness of cord blood banking among pregnant women in semi urban area and found that about two thirds of pregnant women had positive attitude towards preserving umbilical cord blood and beneficial use in future.

There was a strong positive correlation between total knowledge scores and the total attitude scores postapplication of the structured health literacy intervention regarding stem cells therapy. This clearly indicates that when the knowledge level was increased, the attitude was changed positively regarding stem cells therapy among the studied mothers. These outcomes were in harmony with Shineha et al., (2018) who examined knowledge and attitude about stem cells among mothers and concluded a positive attitude toward updating their knowledge regarding stem cell banking. While, these results were in discrepancy with Hans and Kaur, (2016) who reported that knowledge and attitude of women with reference to stem cells and umbilical cord blood banking had a weak positive correlation.

The current study results revealed that there was a relationship between total mothers' knowledge score, attitude and educational level in post-application of the structured health literacy intervention regarding stem cells therapy. From the researchers' point of view, these findings could be interpreted by the higher level of mothers education, the greater improvement in their knowledge' level post-application of the structured health literacy intervention regarding stem cells therapy and this was clarified from mothers demographics characteristics, as nearly three-quarters of them had intermediate and high level of education. In the same line results by Joshi et al (2017) who concluded that mothers' knowledge level about stem cells therapy and cord blood banking improved with increase in their educational class.

Furthermore, there was a relationship between total mothers' knowledge score and age in post-application of the structured health literacy intervention regarding stem cells therapy. These results may be due to the most of the mothers were in the childbearing period, educated, married and also attended the outpatient clinics for follow up of their children who suffers from several chronic diseases. These characteristics made the mothers keen to know about the hope in modern treatments as stem cells therapy, which led to some change in their attitudes positively. This finding is seen as inconsistent with Habib et al (2017) who reported that none of the demographic variables were found to have a significant association with knowledge and attitude of mothers.

\section{Conclusion \& Recommendations}

The current study concluded that the application of a structured health literacy intervention showed a significant improvement in mothers' level of knowledge and attitude regarding stem cells therapy. The researchers recommended that; clinical practice guidelines regarding stem cells therapy should be designed and disseminated to the policymakers, to be applied at the outpatients' clinics and to be evaluated for its achieved clinical health outcomes. Supporting training programs should be established for healthcare professionals, especially nurses, to accomplish the expectation and information needs of the mothers. Health literacy intervention and counseling should be done continuously as part of ordinary health education concerning stem cells therapy. Raising the 
mothers' awareness through identification of religion opinion about issues of stem cells therapy through seminars and workshops. Encouragement of a positive attitude towards stem cells research and treatment through educational programs and campaigns to be implemented by the Ministry of Health and Population. Replication of the study on a larger probability sample should be done to achieve more results that are generalizable.

\section{Acknowledgment}

The researchers thank all mothers who participated in the study for their time and efforts.

\section{Conflict of interest}

The author(s) declared no potential conflicts of interest with respect to the research.

\section{References}

Bae, S. H. (2013). Recent achievements in stem cell therapy for pediatric gastrointestinal tract disease. Pediatric gastroenterology, hepatology \& nutrition, 16(1), 10-16.

De Windt, T. S., Hendriks, J. A., Zhao, X., Vonk, L. A., Creemers, L. B., Dhert, W. J., ... \& Saris, D. B. (2014). Concise review: unraveling stem cell cocultures in regenerative medicine: which cell interactions steer cartilage regeneration and how? Stem cells translational medicine, 3(6), 723-733.

EdwinFrancis C., Deenajothy R., Hemamalini M. \&Titus Immanuel D.C. (2016): Effectiveness of structured teaching program on knowledge regard stem cells and cord blood banking among antenatal mothers at Mmogappair, CHENNAI. International Journal of Pharmacy and Biological Sciences; 6 (1) 135-141.

Habib F, ALFozan H, Prince J, Albylwi A M, AlQadoom B N \& Almutairi M S. (2017). Evaluation of knowledge and attitude of pregnant Saudi women toward cord blood donation. Journal of Health, Medicine and Nursing; 44. 53-62.

Hans, N., \& Kaur, S. (2016). Effectiveness of structured teaching programme on knowledge regarding menstrual blood stem cells banking among nursing students. International Journal of Reproduction, Contraception, Obstetrics and Gynecology, 3137-3140. doi:10.18203/2320-1770.ijrcog20163001

Harris, J., Springett, J., Booth, A., Campbell, F., Thompson, J., Goyder, E., \& Yang, Y. (2015). Can communitybased peer support promote health literacy and reduce inequalities? A realist review. Journal of Public Health Research, 3(3).

Jackie Foster MPH, R. N., Idossa, L., \& Elizabeth Murphy EdD, R. N. (2016). Applying health literacy principles: Strategies and tools to develop easy-to-read patient education resources. Clinical journal of oncology nursing, 20(4), 433.

Joo, K. M., \& Lee, Y. E. (2018). Stem Cell-Based Gene Therapy in Neurological Disorders. Gene Therapy in Neurological Disorders, 81-94. doi:10.1016/b978-0-12-809813-4.00004-1.

Joshi, U., Charan, G. S., \& Kumari, L. (2017). A Study to Assess the Knowledge on Umbilical Cord Stem Cell Collection, Preservation and Utilization among Nurses in the Selected Hospitals at Jalandhar, Punjab. International $\mathrm{J}$ of Health Sciences and Research, 7(8), 227-33.

Karagiorgou, L. Z., Pantazopoulou, M. N. P., Mainas, N. C., Beloukas, A. I., \& Kriebardis, A. G. (2014). Knowledge about umbilical cord blood banking among Greek citizens. Blood transfusion, 12(Suppl 1), s353.

Kickbusch, I., Pelikan, J. M., Apfel, F., \& Tsouros, A. D. (2017). Health literacy: The solid facts. 2013. World Health Organization, Regional Office for Europe,[http://www. euro. who. int/_data/assets/pdf_file/0008/190655/e96854.pdf].

Matsumoto, M. M., Dajani, R., \& Matthews, K. R. (2015). Cord blood banking in the Arab world: current status and future developments. Biology of Blood and Marrow Transplantation, 21(7), 1188-1194.

Nisha Philip and Seeta Devi.2017, Improve The Knowledge And Attitude of Antenatal Mothers Regarding Umbilical Cord Stem Cell Banking. Int J Recent Sci Res. 8(6), pp. 17303-17308. DOI: http://dx.doi.org/10.24327/ijrsr.2017.0806.0327

Pandey, D., Kaur, S., \& Kamath, A. (2016). Banking umbilical cord blood (UCB) stem cells: awareness, attitude and expectations of potential donors from one of the largest potential repository (India). PloS one, 11(5), e0155782.

Patyal, N., Sarin, J., Kaur, R., Singh, R., Kaur, R., Kumar, S., \& Kaur, S. (2018). A study to assess the knowledge and attitude of nurses regarding stem cell and umbilical cord blood banking in selected hospital of Ambala, Haryana. The Pharma Innovation Journal, 7(6), 154-159.

Peberdy, L., Young, J., Massey, D. L., \& Kearney, L. (2018). Parents' knowledge, awareness and attitudes of cord blood donation and banking options: an integrative review. BMC pregnancy and childbirth, 18(1), 395.

Poomalar G. K \&Jayasree M. (2016). Awareness of cord blood banking among pregnant women in semi urban area. Int J Reprod Contracept Obstet Gynecol; 5(8): 2601-2606.

Raju, M. R. (2018). A Study to Assess the Knowledge Regarding Blood Donation among the Adolescents of Selected Colleges in Pune City. Journal of Medical Science And Clinical Research,6(5). 
doi:10.18535/jmscr/v6i5.107

Saran, M. K., Lakshminarayan, N., Kumar, M., \& Shanmukha, G. (2015). Knowledge and awareness of stem cells among expectant mothers and parents of elementary school children in Bareilly and Delhi cities. Journal of Indian Association of Public Health Dentistry, 13(4), 502.

Shen, M., Hu, M., Liu, S., Chang, Y., \& Sun, Z. (2015). Assessment of the Chinese Resident Health Literacy Scale in a population-based sample in South China. BMC Public Health, 15(1), 637.

Shineha, R., Inoue, Y., Ikka, T., Kishimoto, A., \& Yashiro, Y. (2018). A comparative analysis of attitudes on communication toward stem cell research and regenerative medicine between the public and the scientific community. Stem cells translational medicine, 7(2), 251-257.

Slack, J. M. (2018). The Science of Stem Cells. John Wiley \& Sons.

Sørensen, K., Broucke, S. V., Pelikan, J. M., Fullam, J., Doyle, G., Slonska, Z., Brand, H. (2013). Measuring health literacy in populations: Illuminating the design and development process of the European Health Literacy Survey Questionnaire (HLS-EU-Q). BMC Public Health, 13(1). doi:10.1186/1471-2458-13-948.

Stem Cell Bank | Egypt | Cell Safe Bank. (n.d.). Retrieved from https://www.cellsafebank.com/

Tork, H. M., Alraffaa, S. M., Almutairi, K. J., Alshammari, N. E., Alharbi, A. A., \& Alonzi, A. M. (2017) Stem cells: knowledge and attitude among health care providers in Qassim region, KSA. International Journal of Advanced Nursing Studies, 7(1), 1. Doi: 10.14419/ijans.v7il.8524

Venugopal, A., Joshi, P., Deka, D., \& Seth, T. (2016). Knowledge and attitude of nurses regarding stem cells an. Asian Journal of Nursing Education and Research, 6(2), 240. 